\title{
Metabolomic analysis by UAE-GC MS and antioxidant activity of Salvia hispanica (L.) seeds grown under different irrigation regimes
}

Bruna de Falco, Alberto Fiore, Rocco Bochicchio, Mariana Amato, Virginia Lanzotti

This is the accepted manuscript $\odot$ 2017, Elsevier Licensed under the Creative Commons Attribution-NonCommercialNoDerivatives 4.0 International (CC BY-NC-ND 4.0) http://creativecommons.org/licenses/by-nc-nd/4.0/ $($ co) EY-Ne-NO

The published article is available from doi: https://doi.org/10.1016/j.indcrop.2017.12.030 
Metabolomic Analysis by UAE-GC MS and antioxidant activity of Salvia hispanica (L.) seeds grown under different irrigation regimes

3

4 Bruna de Falco ${ }^{\mathrm{a}, \mathrm{b}}$, Alberto Fiore ${ }^{\mathrm{b}}$, Rocco Bochicchio ${ }^{\mathrm{c}}$, Mariana Amato ${ }^{\mathrm{c}}$, and Virginia Lanzotti ${ }^{\mathrm{a} *}$ 5

6 a Dipartimento di Agraria, Università di Napoli Federico II, Via Università 100, I-80055 Portici, $7 \quad$ Naples, Italy

$8{ }^{\mathrm{b}}$ School of Science, Engineering \& Technology, Division of Food \& Drink, University of Abertay, 9 Bell Street, DD1 1HG Dundee, Scotland

$10{ }^{\mathrm{c}}$ Scuola di Scienze Agrarie, Forestali, Alimentari ed Ambientali, Università della Basilicata, viale 11 dell'Ateneo Lucano 10, I-85100 Potenza, Italy

12

13

14

15

16

17

18

*To whom correspondence should be addressed. Tel.: +39 081 2539459; fax: +39 0817754942.

19

E-mail address: lanzotti@unina.it (V. Lanzotti).

20

21

22

23 Running Title: Metabolomics and antioxidant activity of chia seeds and the effect of irrigation 24 
Abstract

Chia (Salvia hispanica L.) is an emerging crop with a high content of $\alpha$-linolenic acid and metabolites of industrial and pharmaceutical interest but information on metabolome variations in response to agricultural management is scarce. We investigated the yield and metabolic profile of the seeds of two chia populations, one commercial black (B) and one long-day flowering genotype (G8), in response to two irrigation levels: replacement of $100 \% \mathrm{ET}_{0}(\mathrm{I})$ or rainfed (NI). Seed yield was higher in irrigated plots in G8 only $\left(0.255 \mathrm{~kg} \mathrm{~m}^{-2}\right.$ for I vs $0.184 \mathrm{~kg} \mathrm{~m}^{-2}$ for NI) while it was very low regardless of irrigation in B due to late flowering. Ultrasound assisted extraction (UAE) of seeds followed by gas chromatography-mass spectrometry (GC/MS) analysis showed differences in fatty acids and the major classes of organic compounds due to both genotype and irrigation, especially in the non-polar phase where irrigated samples showed a higher content of $\alpha$-linolenic and other fatty acids and a lower oleic/linoleic ratio (47.4 in NI vs. 39.6 in I). The antioxidant activity, expressed as trolox equivalent antioxidant capacity (TEAC), ranged from $1.317 \pm 0.027$ to $2.174 \pm 0.010 \mathrm{mmol}$ TEAC/g of defatted chia seed after 2 and 40 min respectively, and was negatively affected by irrigation. The total polyphenolic content (TPC) measured with the Folin-Ciocalteu method, also decreased with irrigation. According to our results irrigation can affect chia yield, metabolome and antioxidant behavior but some of the effects are genotype-dependent.

Keywords: Chia; Polyphenols; TPC; Management; Alpha-linolenic acid; Quality 


\section{Introduction}

48 Chia (Salvia hispanica L.) is an ancient short-day flowering crop with center of origin between Mexico and Guatemala (Cahill, 2004). It was one of the staple crops in pre-Columbian Central America but its diffusion was drastically reduced after the Spanish domination. Chia was rediscovered in the 90 s by researchers intending to propose alternative crops to farmers (Coates, 1996; Gentry et al., 1990), and has thereafter spread to several areas of the world, at first due to favorable market placement linked to its nutraceutical properties, and more recently as a source of compounds of cosmetic, medical and industrial interest (Hermoso-Diaz et al., 2014; Lu and Foo, 2002; Muñoz et al., 2013). The Salvia genus includes more than 900 species, and in the New World around 500 species belong to the subgenus Calosphace (Benth.) and may be grouped in complexes of species with common medicinal activity, mostly related to the content of terpenes in leaves. Jenks and Kim (2013) listed external application (antimicrobic, skin problems and rheumatisms) and internal uses (gastro-intestinal, gynecological and neurological) in the mirto complex, primary uses for the respiratory system in the Nucchu complex, and primary uses for biliary and kidney problem in the Li'l ++, Cantueso and Manga-paqui complexes. They also report that S. divinorum Epling and Játiva-M. are the most studied medicinal sage leaves within the Calosphace subgenus, due to their use as a hallucinogen by Mexican shamans and their selective kappa-opioid receptor agonist activity. The chia complex, including 18 species besides S. hispanica (2013), on the other hand, is the most renowned for the production of indehiscent dry fruits, commonly referred to as "seeds", rich in oil. Chia seeds are one of the richest natural sources of omega 3 fatty acids (Ayerza and Coates, 2011; Ayerza, 1995) and show a high content of protein with a balanced composition in essential amino acids (Ayerza, 2013) and fiber (Capitani et al., 2012). A part of the fiber is located in the outer cells of the fruit and is extruded at the fruit surface upon hydration (Muñoz et al., 2012), forming a mucilaginous capsule with rheological properties that make it promising for industrial and medical uses: it is highly hygroscopic, viscous and adhesive (Švec et al., 2016). Many antioxidants have been identified in chia seeds, extracted oil and mucilage, especially phenolic acids and flavonoids, besides poly-unsaturated fatty acids (Amato et al., 2015; da Silva Marineli et al., 2014). Chia seeds or their products are therefore increasingly proposed not only as food but also as a component for biodegradable film (Capitani et al., 2016; Muñoz et al., 2012), thickening agents (Coelho and de las Mercedes Salas-Mellado, Myriam, 2015; Felisberto et al., 2015; Iglesias-Puig and Haros, 2013; Menga et al., 2017), anti-corrosive agents (Hermoso-Diaz et al., 2014), cosmetics (Muñoz et al., 2013) and medicaments (Vuksan et al., 2010). A strong variation in chia seeds' composition has been reported: for instance, oil content ranges from little over $20 \%$ to over $36 \%$ (Ayerza and Coates, 2004; 
80 Ayerza, 1995; Coelho and de las Mercedes Salas-Mellado, Myriam, 2014; da Silva Marineli et al., 81 2014; Ixtaina et al., 2011). Variability has mainly been researched in relation to genotype and environment: Ayerza (2009) reports a range in total fat content from $25.93 \%$ to $33.50 \%$ for the same genotype of chia grown in five different environments. The fatty acids profile, especially the content of $\alpha$-linolenic acid, is also affected by elevation in seeds of this species, even within the same genotype (Ayerza and Coates, 2011; Martínez-Cruz and Paredes-López, 2014). This is probably largely due to thermal effects of elevation, as reported by Ayerza and Coates (2004) who found a correlation between temperature and chia oil fatty acids measured across different environments; they concluded that levels of fatty acids' unsaturation in chia increase at cooler temperatures, as observed for other oil seed crops due to saturase-desaturase dynamics. In an experiment conducted across different countries in America, Ayerza (2009) reports a direct relationship between elevation and oil content and an inverse relationship between elevation and the content of proteins. Several environmental variables might be involved besides temperature, including soil properties and a negative correlation between oil and protein as found in other crops. Ayerza and Coates (2011) suggest that the relationships of oil and protein content and oil saturation with elevation are strong enough that they could be used to trace the growing environment of chia. Ayerza (2009) also found differences in protein content for the same genotypes grown in different environments, but could not prove differences among genotypes within a site, except for one variety at one site. In a further study, Ayerza (2013) could not find significant differences between two genotypes of different seed coat color for protein, oil, fiber, amino acids, and antioxidant content. (Silva et al., 2016) found that a white and a black seed crop with the same seed yield produced different amounts of unsaturated fatty acids: the white seed genotype yielded more linoleic and $\alpha$-linolenic acids $\left(6.0\right.$ and $17.0 \mathrm{~kg} \mathrm{ha}^{-1}$ respectively) than the black seed one (4.4 and $16.7 \mathrm{~kg} \mathrm{ha}^{-1}$ respectively). De Falco et al. (2017b) studied the metabolic profile of the seeds of seven chia populations, including commercial and early flowering mutant genotypes, and showed significant differences in the metabolic fingerprinting of the different populations using nuclear magnetic resonance (NMR) and chemometrics. An investigation of the metabolome with gas chromatography-mass spectrometry has not yet been performed on chia seeds after agronomic management. Very little information is available about the variation in chia seeds composition with agronomic management. Amato et al. (2015) compared nitrogen fertilization regimes on chia seed composition

111 organic nitrogen only, whereas the addition of mineral nitrogen in topdressing increased free acidity, 112 chlorophyll and carotenoids content. De Falco et al. (2017b) reported that the effect of mineral 113 nitrogen supply on chia positively affects the content of aliphatic free amino acids, and negatively 
114 that of the main carbohydrates and flavonoids. Heuer et al. (2002) found that salinity of irrigation 115 water decreases the oil content of chia seeds and increased their content of palmitic and linoleic acids. 116 Irrigation is one of the major agronomical factors conditioning crop yield and composition, and 117 namely that of oilseeds (Flagella et al., 2002). Silva et al. (2016) did not find a significant effect of 118 irrigation on chia seed yield and content of linoleic and $\alpha$-linolenic acids. However authors point out 119 that their experiment was conducted using short-day flowering genotypes at a latitude higher than 120 optimal; due to photoperiod sensitivity flowering was delayed and temperatures during seed 121 maturation were too low to allow complete grain filling. In this condition, temperature and not water 122 was the limiting factor and even fully irrigated plots yielded poorly. More information is therefore 123 needed on the response of chia to irrigation taking photoperiod sensitivity into account. The objective 124 of this research was to study the response of chia to irrigation with the hypothesis that irrigation 125 affects the yield of chia seeds, the fatty acid profile and the production of secondary metabolites found 126 in the polar and non-polar extracts. The hypothesis that responses to irrigation are different in short127 day and long-day flowering genotypes at high latitudes was also tested by using a short-day 128 commercial chia seed source and a long-day flowering mutant.

\section{Materials and methods}

\subsection{Plant material}

131 Black chia (Salvia hispanica L.) seeds (B) were obtained from a commercial retailer (Eichenhain132 Hofgeismar-DE) and seeds of one long-day flowering mutant genotype (G8) were obtained as 133 described in Jamboonsri et al. (2012) and were kindly supplied through an agreement between the 134 University of Basilicata and the University of Kentucky (US).

\subsection{Growth conditions}

Plants were grown in Basilicata (Southern Italy-Lat. N 40 51'37,59" Lon. E $15^{\circ} 38^{\prime} 49,43^{\prime \prime}$ ) on a Luvi-vertic Phaeozem (IUSS, 2007), loam soil (43.6\% of sand, 34.2\% silt and $22.1 \%$ clay) in the period June-December 2014. Soil water content was $0.279 \mathrm{~g} \mathrm{~g}^{-1}$ at $-0.03 \mathrm{MPa}$ and $0.137 \mathrm{~g} \mathrm{~g}^{-1}$ at -1.5

$139 \mathrm{MPa}$. A field factorial randomized block design with three replications was established to test the two genotypes B and G8 with two levels of irrigation:

$141 \quad \mathrm{NI}=$ no irrigation

$142 \mathrm{I}=$ nonlimiting water supply. We provided $100 \%$ of $\mathrm{ET}_{0}$ corresponding to the evaporative demand of 143 the atmosphere (Allen et al., 1998) measured with a TE-ETG atmometer (Tecnoel, Rm Italy). 
145 The irrigation system was drip with pre-installed emitter lines with drippers at $200 \mathrm{~mm}$ distance and 146 maximum flow rate $6.6 \times 10-^{5} \mathrm{~m}^{3} \mathrm{~s}^{-1}$ at $1 \times 10^{5} \mathrm{~Pa}$. Plot size was $8 \times 5 \mathrm{~m}$ with a density of 20 plants $\mathrm{m}^{-}$

1472 . The crop was sown on June 26, 2014. Precipitation and irrigation amounts are shown in Fig.1; total 148 precipitation was $197 \mathrm{~mm}$ during the experiment and all plots received the same initial regime with $14952 \mathrm{~mm}$ of irrigation to help crop establishment. Treatments were differentiated at 51 DAS (day after 150 sowing) when the I treatment was left in rainfed conditions and the I treatment was irrigated receiving $151172 \mathrm{~mm}$ of further irrigation. Evaporation was read daily and irrigation was performed when a set 152 amount was reached. In order to cover the crop's needs for root establishment and full deployment of 153 deep rooting potential, irrigation schedule and amount ranged from irrigation with around $4.5 \mathrm{~mm}$ 154 every 4 days up to $15 \mathrm{DAS}$, to an irrigation amount of around $14 \mathrm{~mm}$ on average per irrigation 155 thereafter. This corresponded to a number and timing of irrigations varying according to evaporation 156 and the timing of precipitation: 5 irrigations in July (with a maximum of 10 days without irrigation 157 due to precipitation), 10 in August (every 2-4 days), 2 in September (with a maximum of 26 days 158 without irrigation due to precipitation) and October (with a maximum of 21 days without irrigation 159 due to precipitation). Seeds of G8 and B were harvested at 132 and 173 DAS respectively, on one 160 sample of 20 plants per replication. A trench dug after harvest showed roots up to $2 \mathrm{~m}$ and a total soil 161 depth exceeding $3 \mathrm{~m}$.

162

163

164

165

166

167

168

169

170

171

172

\subsection{Chemicals and reagents}

The reagents used for the extraction procedure and chemical characterization, namely anhydrous methanol (99.8\%), anhydrous $n$-hexane (95\%), 2,2`-Azinobis-(3-ethylbenzothiazoline-6-sulfonic acid) diammonium salt (ABTS), derivatizating agents methoxyamine hydrochloride and N-methylN-trimethylsilyltrifuoroacetamide (MSTFA) were obtained from Sigma-Aldrich (Dorset, UK). $N, O$ Bis(trimethylsilyl)trifluoroacetamide, Trimethylchlorosilane (BSTFA with 1\% TMCS) was purchased from Supelco Analytical (Bellefonte, PA). Pyridine, anhydrous sodium carbonate, FolinCiocalteu's reagent and gallic acid were obtained from Fischer Scientific (Loughborough, UK). Sugars, amino acids, organic acids and polyphenols used for identification and quantification were purchased from Sigma-Aldrich (Dorset, UK).

\subsection{Extraction procedure of the organic phase}

173 Chia seeds were strained in order to remove extraneous matter such as dust and straw. The clean seeds 174 were blended in a laboratory mill (IKA Works MF10, Scotland, UK) in order to obtain a fine powder 175 of the organic material. Subsequently, the powder $(15 \mathrm{~g})$ was extracted with $80 \mathrm{ml}$ of $n$-hexane for 2 $176 \mathrm{~h}$ under stirring. The mixture was centrifuged at 3700rpm for $10 \mathrm{~min}$ and the supernatant was 
immediately stored at $-80^{\circ} \mathrm{C}$ in the dark for later analysis. The pellet was washed twice with $20 \mathrm{ml}$ of $n$-hexane and then centrifuged at $3700 \mathrm{rpm}$ for $10 \mathrm{~min}$. The supernatant was added to the previous fraction and the leftover pellet was left overnight in a fume hood in order to remove the excess solvent.

\subsection{Ultrasound assisted extraction (UAE)}

The defatted chia seeds (10g) were extracted with 100ml of methanol/water (60:40). Sonication was performed at $20 \mathrm{kHz}$ with 50\% power using a Fischer Scientific Ultrasound (model FB705, 700W, 2000 Park Lane, Pittsburgh, PA) with continuous stirring. The probe was a horn-type (model CL334 ), which was kept at constant depth in the mixture using a $250 \mathrm{ml}$ glass beaker of standard dimensions. During the extraction, the temperature was monitored and kept constant $\left(25^{\circ} \mathrm{C} \pm 1\right)$ using a thermostatic bath. Samples $(5 \mathrm{ml})$ were collected after 2, 20, $40 \mathrm{~min}$ and centrifuged at 2500rpm for $10 \mathrm{~min}$. The supernatant was stored at $-80^{\circ} \mathrm{C}$ for later analysis.

\subsection{Total polyphenol content}

Total polyphenolic content (TPC) was determined by spectrophotometry according to the method described by Singleton and Rossi (1965) with some modifications: $125 \mu 1$ of diluted sample (1:10) were mixed with $500 \mu \mathrm{l}$ of distilled water and $125 \mu \mathrm{l}$ of Folin-Ciocalteu reagent. After $6 \mathrm{~min}, 1.25 \mathrm{ml}$ of a $7.5 \%$ sodium carbonate solution were added to the mixture and brought to a final volume of $3 \mathrm{ml}$ with distilled water. The test tubes were then allowed to stand in the dark for $90 \mathrm{~min}$ at room temperature. The absorbance was read at 760nm (Thermo Scientific Genesys 10S UV-Vis Spectrophotometer) and TPC was expressed in terms of gallic acid equivalents (GAE/g). A calibration curve ranging from 20 to $200 \mu \mathrm{g} \mathrm{ml}^{-1}$ was used to quantify the TPC content in the seed extracts. All determinations were performed in triplicate.

\subsection{Antioxidant activity}

The free radical-scavenging activity was determined according to Re et al., (1999) using the reduction of radical cation 2,2 -Azinobis-(3-ethylbenzothiazoline-6-sulfonic acid) diammonium salt (ABTS ${ }^{\bullet+}$ ). A mixture of $2.5 \mathrm{ml}$ of $7 \mathrm{mM}$ ABTS and $44 \mu \mathrm{l}$ of $140 \mathrm{mM}$ potassium persulfate was prepared and left overnight in the dark. The spectrophotometer wavelength was set at $734 \mathrm{~nm}$. The stock solution of ABTS was diluted to 1:80 until a final OD (optical density) reached a value between 0.7 and 0.8nm. Samples were diluted 1:10 and $100 \mu \mathrm{l}$ were added to $1 \mathrm{ml}$ of ABTS solution. After $2.5 \mathrm{~min}$ the reduction was measured as the percentage of inhibition. Results were expressed in mmol Trolox 
206 equivalent antioxidant capacity (TEAC/g) and referred to a calibration curve ranging from 25 to $207250 \mu \mathrm{M}$. All determinations were performed in triplicate.

\subsection{Derivatization and GC/MS analysis}

209 In order to obtain volatile and stable compounds, both polar and non-polar extracts were derivatized 210 before analysis by GC/MS. For this purpose, the organic phase was dried under nitrogen stream and 211 a stock solution (500ppm) was prepared. A subsample of $75 \mu 1$ was dissolved in $300 \mu 1$ of 212 pyridine/BSTFA $+1 \%$ TMCS (1:1). The vials were vortexed, left at $25^{\circ} \mathrm{C}$ for $15 \mathrm{~min}$ and analyzed 213 by GC/MS (Shareef et al., 2006). The metabolomic analysis of the polar extract needed a two-step 214 process, starting with oximation to reduce tautomerism of aldehydes and ketones, followed by $\mathrm{OH}$, 215 SH and NH silylation (Gullberg et al., 2004). An aliquot $(200 \mu \mathrm{l})$ of diluted sample (1:50) was 216 evaporated to dryness in a vacuum centrifuge (Eppendorf Concentrator 5301) and oxymated with $21750 \mu 1$ of methoxyamine hydrochloride $\left(20 \mathrm{mg} \mathrm{ml}^{-1}\right)$ in pyridine at $60^{\circ} \mathrm{C}$ for $45 \mathrm{~min}$. Samples were then 218 silylated with MSTFA at $60^{\circ} \mathrm{C}$ for $45 \mathrm{~min}$. Both polar and non-polar extracts were analyzed in a 219 similar way by gas chromatography - mass spectrophotometry. Derivatized samples were injected $220(1 \mu \mathrm{l})$ in a pulsed splitless mode into an Agilent-7820A GC system with 5977E MSD operating in EI 221 mode at $70 \mathrm{eV}$. The system was equipped with a $30 \mathrm{~m} \times 0.25 \mathrm{~mm}$ id fused-silica capillary column with $2220.25 \mu \mathrm{m}$ HP-5MS stationary phase (Agilent technologies, UK). The injection temperature was set at $223270^{\circ} \mathrm{C}$. Helium was used as carrier gas at a constant flow rate of $1 \mathrm{ml} \mathrm{min}^{-1}$. Separation of the non224 polar extract was achieved using a temperature program of $80^{\circ} \mathrm{C}$ for $1 \mathrm{~min}$, then ramped at $10^{\circ} \mathrm{C} / \mathrm{min}$ to $320^{\circ} \mathrm{C}$ and held for $1 \mathrm{~min}$. The analysis of the polar compounds was performed under the following temperature program: $2 \mathrm{~min}$ of isothermal heating at $70^{\circ} \mathrm{C}$, followed by a $10^{\circ} \mathrm{C} / \mathrm{min}$ oven temperature ramp to $320^{\circ} \mathrm{C}$, and a final $2 \mathrm{~min}$ at $320^{\circ} \mathrm{C}$. The system was then temperature equilibrated for $1 \mathrm{~min}$ at $70^{\circ} \mathrm{C}$ before injection of the next sample. All spectra were recorded in the mass range 50 to 800 $m / z$. Both chromatograms and mass spectra were evaluated using the MassHunter Qualitative Analysis B.07.00 (Agilent Technologies, CA, USA). Mass spectra of all detected compounds were compared with standard compounds and with spectra in National Institute of Standard and Technologies library NIST MS Search 2.2 (https://www.nist.gov). Data was processed with the AMDIS (Agilent Technologies, CA, USA) software to deconvolute co-eluting peaks. Artifact peaks, such as peaks due to derivatizing agents, were not considered in the final analyses. Peak areas of multiple peaks belonging to the same compound were summed together. The relative amount of separated metabolites was calculated from Total Ion Chromatography (TIC) by the computerized integrator and with the internal standard, malonic acid and 1-oleoyl-rac-glycerol, added to polar and non-polar extracts respectively. 
240 Relative quantification was done by integrating the peak areas of the chromatographic profiles for 241 each compound and normalizing the data to the internal standards. The effect of genotype, irrigation and their interaction on the chemical composition of chia seeds was evaluated through the analysis of variance with the $\mathrm{R}$ software (RDevelopment, 2012) after checking for normality and 244 homoscedasticity of data.

\section{3. Results and Discussion}

\section{$246 \quad 3.1$ Seed production and chemical properties}

247 The genotype $\mathrm{x}$ irrigation interaction for seed yield is reported in Fig. 1. Yields of G8 were in the 248 high yielding end of the range of productive data reported for chia worldwide (Bochicchio et al., 249 2015a) and were significantly higher than those of B. Irrigated plots yielded more than NI but statistical significance of this difference was reached in G8 only. Results confirm first reports of low yields from traditional genotypes of chia grown at high latitudes (Bochicchio et al., 2015b; Silva et 252 al., 2016). Traditional genotypes are microthermal and short-day flowering, therefore are sown in late 253 spring and cannot flower until late summer; seed ripening occurs in fall-winter and is hampered by 254 low temperatures. Besides low yields, this explains the lack of significant effects of irrigation on the 255 short-day flowering genotype since temperature during ripening becomes the limiting factor for this chia type and makes it difficult to detect yield differences due to other factors. This confirms the results of Silva et al. (2016) who also report non-significant irrigation effects on a short-day flowering genotype grown at high latitude.

259 Oil yield (Fig. 1) was $39.6 \%$ on average without significant differences between treatments. This 260 value is in the high range of chia seeds oil content (Bochicchio et al., 2015a).

261 The TPC results, expressed as $\mathrm{mg} \mathrm{GAE} / \mathrm{g}$ of defatted chia seed, were in agreement with Amato et al. 262 (2015) and with other previous reports (Coelho and de las Mercedes Salas-Mellado, Myriam, 2014; 263 Reyes-Caudillo et al., 2008) but lower compared to data reported by da Silva Marineli et al. (2014). 264 The polyphenol content increased after $40 \mathrm{~min}$ of $\mathrm{UAE}(\mathrm{p}<0.01)$. Although in many cases values were 265 lower in irrigated treatments, differences were statistically significant $(\mathrm{p}<0.01)$ only for the 266 commercial variety at 2 minutes, and sample variability did not allow significance to be reached in 267 the other instances. The general trend of our data agrees with literature reports of a negative effect of 268 irrigation on TPC for different species (Dag et al., 2008; Esteban et al., 2001). 
270 The antioxidant activity of chia seeds was also evaluated and Fig. 1 shows the TEAC results for Black 271 chia and G8 seeds. The values ranged from $1.317 \pm 0.027$ to $2.174 \pm 0.010 \mathrm{mmol} \mathrm{TEAC/g}$ of defatted 272 chia seed, measured after 2 and $40 \mathrm{~min}$, respectively. These results are in agreement with Sargi et al. 273 (2013), but higher than those reported by other authors (Capitani et al., 2012; Vázquez-Ovando et al., 274 2009). Values were lower in irrigated treatments, but differences were statistically significant 275 ( $\mathrm{p}<0.01)$ only for G8 at 2 minutes. In many plant species, the amount of antioxidants and/or 276 antioxidant activity is shown to increase (Wu et al., 2017) or remain unaffected (Kyraleou et al., 2016) 277 with reduced water supply. Zhang and Kirkham (1996) show that the degree to which the activities of antioxidant enzymes and the amount of antioxidants change under drought stress is variable with plant species. No reports of chia antioxidant activity in response to irrigation are available, but Amato et al. (2015) found a reduction in oxidative stability and phenols in response to mineral nitrogen fertilization.

\subsection{Metabolite profile}

A whole metabolome profile of two different genotypes (G8 and Black chia) of Salvia hispanica L. seeds was evaluated by GC/MS analysis. All compounds from the polar and non-polar extracts with their respective retention times and $\mathrm{m} / \mathrm{z}$ values are listed in Table 1 , and representative total ion chromatograms (TIC) for both fractions are reported in Fig. 2. Our assignments from GC/MS are in agreement with those obtained using NMR and chemometrics by de Falco et al. (2017b) who performed a metabolomic fingerprinting of different populations of $S$. hispanica including G8 and Black chia seeds. The GC/MS approach, however, allowed us to identify compounds which were not detected by previous work such as the 10-heptadecenoic acid (17:1) and the comparison of irrigation treatments allowed us to detect responses (Table 2) which were not investigated by other experiments.

\subsection{Non-polar phase}

The main fatty acids detected in chia seeds were linolenic acid (18:3), linoleic acid (18:2), stearic acid (18:0), palmitic acid (16:0) and oleic acid (18:1), determined as trimethylsilyl (TMS) derivatives. These compounds were previously detected in other reports (Amato et al., 2015; Peiretti and Gai, 2009). A preliminary analysis of chromatograms showed C18:3 as the most abundant fatty acid in all samples. On the contrary, 10-heptadecenoic acid (17:1) was detected in the lowest amount. This 
compound was also reported as one of the least abundant by Segura-Campos et al. (2014) and da 299 Silva Marineli et al. (2014).

300 MS spectrum of saturated fatty acids trimethylsilyl esters such as C16:0 and C18:0 have a base peak 301 at $m / z 313$ and 341 respectively, which represents the loss of methyl group from TMS ester group, 302 while $m / z 132$ represents the McLafferty rearrangement ion. In the MS spectrum of monounsaturated 303 and polyunsaturated TMS fatty acids, such as C18:1, C18:2 and C18:3 characteristic peaks for each 304 of them were detected at $m / z 339,337$ and 335, respectively. Also in these chromatograms, a base 305 peak at $m / z$ 73, due to TMS, was always detected. As shown in Fig. 3, the most abundant fatty acid 306 is $\alpha$-linolenic acid (C18:3) in all samples, and this is in agreement with those of other reports (Coelho 307 and de las Mercedes Salas-Mellado, Myriam, 2014; de Falco et al., 2017a). Analysis of variance on 308 the non-polar fraction (Table 2) shows that the main effects of genotype and irrigation were 309 significant in many cases. In particular, the total amount of fatty acids was found higher in G8 than 310 in B, except for $\mathrm{C} 17: 1$ which was higher in B, and oleic acid (C18:1) and glycerol monostearate 311 (GMS) which were not significantly different between genotypes. Although irrigation treatment 312 affected the fatty acids composition of both genotypes of chia seeds, an interaction was significant in 313 C18:1 where values of the irrigated treatment were higher than NI only for G8, and in GMS where $314 \mathrm{I}<\mathrm{NI}$ in G8 and I>NI in B. Silva et al. (2016) reported that irrigation did not affect significantly the 315 content of linoleic and $\alpha$-linolenic acids of chia, but their experiment tested less extreme levels of 316 irrigation, ranging between $40 \%$ and $100 \%$ of $\mathrm{ET}_{0}$, whereas in our case $100 \%$ of $\mathrm{ET}_{0}$ is compared 317 with rainfed conditions. No metabolomic study on the effect of irrigation on chia seeds is found in 318 the literature, and few reports on the effect on single metabolites are available: Silva et al. (2016) did 319 not find differences in linoleic and $\alpha$-linolenic acids content of chia seeds grown in different irrigation 320 regimes, and Heuer et al. (2002) found an increase in the levels of palmitic and linoleic acids in 321 response to salinity in irrigation water. In other species irrigation is reported to affect fatty acids 322 composition but results are often contradictory. Erdemoglu et al. (2003) found a decrease in the 323 content of linoleic and oleic acids with irrigation in sunflower seed oil. Sezen et al. (2011) found an 324 increase in linoleic, palmitic and stearic acid concentrations with irrigation. Bellaloui et al. (2015) reported that irrigation affects soybean oil composition differently according to the degree and stage of differentiation of water treatments. Ayerza (2009) reports a negative correlation of the percentages of oleic and linoleic acid in chia samples from different environments. This is found in many crops, 328 due to the dynamics of oleate desaturases: an increase of desaturation in cold conditions causes a 329 decrease of the oleic/linoleic acids ratio in cooler environmental temperatures (Aparicio et al., 1994). 330 In our data, although the amount of many fatty acids increases in response to irrigation, the response 331 is proportionally lower in oleic acid, and therefore the oleic/linoleic ratio decreases from 47.4 in the 
rainfed samples to 39.6 in the irrigated treatments. Flagella et al. (2002) observed a decrease in the

333 oleic/linoleic acid ratio in sunflower in response to irrigation, and suggested that a possible thermal 334 effect of irrigation may have affected the activity of oleate desaturase.

\subsection{Polar phase}

In the aqueous extracts sugars are the principal class of compounds and the disaccharide sucrose $(\mathrm{m} / \mathrm{z}$ 361) represents the major component followed by methyl galactose as the major monosaccharide component (Table 1). Other sugars identified were glucose, galactose, fructose, mannitol and gluconic acids. In particular, TMS derivatives of monosaccharides such as glucose and galactose showed a very similar GC/MS profiles, due to their stereoisomery, with characteristic ions observed at $m / z, 147,205,319$ and 364 . The final identification of these compounds was achieved by comparing their elution order with literature data (Gómez-González et al., 2010) and by injection of standard samples. Other compounds detected were the polyphenol caffeic acid, the polyol myo-inositol and a series of carboxylic acids and amino acids (Table 1). A base peak at $m / z 73$, typical of silylated compounds, was always detected in the chromatograms due to the $\left[\left(\mathrm{CH}_{3}\right)_{3} \mathrm{Si}\right]$ group. In the polar fraction (Fig. 4) sucrose (Sucr) and methyl-galactoside (mGal) are the most abundant sugars present in all samples, while within organic acids, lactic acid (LA) and citric acid (CI) have the highest value, followed by quinic acid (QUI).

349 Caffeic acid (CA) did not exhibit variation within genotype, but even if statistically not significant, its level is higher in Black chia than G8. Values were more variable than those of the non-polar phase, and statistical significance of the differences between genotype and irrigation treatments was not reached for many compounds (Fig. 4). A genotype effect was significant for some compounds (Fig. 4): G8 showed a significantly higher amount of lactic acid (LA), benzoic acid (BE) and serine (Ser), while B showed a significantly higher amount of gluconic acid (GLUC), arabitol (Ara) and sugars, in particular mannose (Man). The overall effects of irrigation were not significant but interactions were found for some compounds (Fig. 4): irrigated samples showed significantly higher values of glycine (Gly) in G8 only, and significantly lower values of Asp and phenylalanine (Phe) in B only. No reports of chia polar extracts variation in response to irrigation are available in the literature. The only other data regarding agricultural management effects on chia seeds whole metabolome are related to nitrogen fertilization and point out a positive effect of mineral nitrogen topdressing on the content of

361 aliphatic free amino acids, a reduction of carbohydrates and flavonoids and no effect on the pools of caffeoyl derivatives and organic acids (de Falco et al., 2017b). 


\section{Conclusion}

364 This work provides a high-throughput analysis of metabolomic fingerprinting including total 365 polyphenolic content (TPC) and antioxidant activity (TEAC), on commercial black chia and early 366 flowering G8 seeds. The analytical approach performed by UAE-GC MS allowed detection and 367 quantification of a high number of metabolites.

368 The aim of the paper was to evaluate the difference in organic compounds between a commercial 369 genotype, black chia, and the recently developed mutant G8. The species were grown at different 370 levels of irrigation to evaluate the effect of water supply on the metabolite content. Results showed 371 an increase of TPC and antioxidant activity (expressed as TEAC) in all samples relative to irrigation 372 treatment or variety after 40 minutes of UAE. On the contrary a decrease of TPC and TEAC levels 373 was observed after irrigation treatments. With regards to the non-polar phase, quantitative analysis 374 showed a higher yield and content of many fatty acids including $\omega$-3 ( $\alpha$-linolenic), in the early 375 flowering G8 mutant, with a decrease of the ratio of oleic/linoleic acids. Concerning the polar fraction, 376 sugars were found as the main metabolites with sucrose and methyl galactose as the major 377 components. The genotype effect has more influence than the irrigation treatment on the aqueous 378 extract. G8 showed significantly higher amounts of some organic acids and amino acids, such us LA, 379 BE and Ser while GLUC, Ara and Mann are present in lower amounts.

380 Gas chromatography-mass spectrometry can provide a detailed metabolic profile of chia seeds 381 extracted with ultrasound. Furthermore, this study highlighted for the first time the effects of 382 irrigation on the metabolome of a late flowering and an early flowering mutant chia genotypes.

383 In addition, this approach proved that chia seeds of mutant genotypes can be cultivated at high latitude 384 without loss in nutraceuticals. Within mutants, G8 can be proposed as excellent early-flowering 385 genotype.

386 The obtained data indicate that metabolomics could be used as monitoring technique to control the 387 agronomic management and its non-invasive features making it an ideal tool for crop production.

\section{Acknowledgements}

390 We thank the University of Kentucky, USA, for kindly providing the chia genotype G8 through the 391 framework of a Memorandum of Understanding with the University of Basilicata, Italy. GC/MS 392 spectra were recorded at University of Abertay. The assistance of the staff is gratefully acknowledged. 393 We thank Dr. Morag Steele for the English mother language revision of manuscript. 
396 The authors declare no competing financial interest.

397

398

399 
401 Allen, R.G., Pereira, L.S., Raes, D., Smith, M., 1998. FAO Irrigation and drainage: Crop 402 evapotranspiration. Guidelines for computing crop water requirements. No. 56. Rome: Food and 403 Agriculture Organization of the United Nations, 56, 1-156.

404 Amato, M., Caruso, M.C., Guzzo, F., Galgano, F., Commisso, M., Bochicchio, R., Labella, R., Favati, 405 F., 2015. Nutritional quality of seeds and leaf metabolites of Chia ( Salvia hispanica L.) from 406 Southern Italy.(Report)(Author abstract), European Food Research \& Technology 241, 615. doi: 407 $10.1007 / \mathrm{s} 00217-015-2488-9$.

409 olive oil, Anal. Chim. Acta 292, 235-241.

Ayerza H, R., Coates, W., 2011. Protein content, oil content and fatty acid profiles as potential criteria to determine the origin of commercially grown chia ( Salvia hispanica L.), Industrial Crops \& 412 Products 34, 1366-1371. doi: 10.1016/j.indcrop.2010.12.007.

413 Ayerza, R., Coates, W., 2004. Composition of chia (Salvia hispanica) grown in six tropical and 414 subtropical ecosystems of South America, Tropical Science 44, 131-135.

415 Ayerza, R., 2009. The seed's protein and oil content, fatty acid composition, and growing cycle length 416 of a single genotype of chia (Salvia hispanica L.) as affected by environmental factors, Journal of 417 Oleo Science 58, 347-354.

418 Ayerza, R., 1995. Oil content and fatty acid composition of chia (Salvia hispanica L.) from five northwestern locations in Argentina, J. Am. Oil Chem. Soc. 72, 1079-1081.

Ayerza, R., 2013. Seed composition of two chia (Salvia hispanica L.) genotypes which differ in seed color.(FOOD SCIENCE AND NUTRITION), Emirates Journal of Food and Agriculture 25, 495. doi: 10.9755/ejfa.v25i7.13569.

Bellaloui, N., Bruns, H.A., Abbas, H.K., Mengistu, A., Fisher, D.K., Reddy, K.N., 2015. Agricultural practices altered soybean seed protein, oil, fatty acids, sugars, and minerals in the Midsouth USA, Front. Plant. Sci. 6, 31. doi: 10.3389/fpls.2015.00031 [doi].

Bochicchio, R., Philips, T.D., Lovelli, S., Labella, R., Galgano, F., Di Marisco, A., Perniola, M., Amato, M., 2015a. Innovative crop productions for healthy food: the case of Chia (Salvia hispanica L.). In: Anonymous The Sustainability of Agro-Food and Natural Resource Systems in the Mediterranean Basin. Springer, pp. 29-45. 
430 Bochicchio, R., Rossi, R., Labella, R., Bitella, G., Perniola, M., Amato, M., 2015b. Effect of sowing 431 density and nitrogen top-dress fertilisation on growth and yield of chia (Salvia hispanica L.) in a 432 Mediterranean environment: first results, Italian Journal of Agronomy 10, 163-166.

433 Cahill, P., 2004. Genetic diversity among varieties of chia (Salvia hispanica L.), Genet. Resour. Crop 434 Evol. 51, 773-781.

435 Capitani, M., Matus-Basto, A., Ruiz-Ruiz, J., Santiago-García, J., Betancur-Ancona, D., Nolasco, S., 436 Tomás, M., Segura-Campos, M., 2016. Characterization of Biodegradable Films Based on Salvia 437 hispanica, Food and Bioprocess Technology 9, 1276-1286.

438 Capitani, M.I., Spotorno, V., Nolasco, S.M., Tomás, M.C., 2012. Physicochemical and functional 439 characterization of by- products from chia (Salvia hispanica L.) seeds of Argentina, LWT - Food 440 Science and Technology 45, 94-102. doi: 10.1016/j.lwt.2011.07.012.

441 Coates, W., 1996. Production potential of chia in northwestern Argentina, Industrial Crops and 442 Products 5, 229-233.

443 Coelho, M.S., de las Mercedes Salas-Mellado, Myriam, 2015. Effects of substituting chia (Salvia 444 hispanica L.) flour or seeds for wheat flour on the quality of the bread, LWT-Food Science and 445 Technology 60, 729-736.

446 Coelho, M.S., de las Mercedes Salas-Mellado, Myriam, 2014. Chemical characterization of Chia 447 (Salvia hispanica L.) for use in food products, Journal of Food and Nutrition Research 2, 263-269.

448 da Silva Marineli, R., Moraes, ÉA., Lenquiste, S.A., Godoy, A.T., Eberlin, M.N., Maróstica Jr, M.R., 449 2014. Chemical characterization and antioxidant potential of Chilean chia seeds and oil (Salvia 450 hispanica L.), LWT-Food Science and Technology 59, 1304-1310.

451 Dag, A., Ben-Gal, A., Yermiyahu, U., Basheer, L., Nir, Y., Kerem, Z., 2008. The effect of irrigation 452 level and harvest mechanization on virgin olive oil quality in a traditional rain-fed 'Souri'olive 453 orchard converted to irrigation, J. Sci. Food Agric. 88, 1524-1528.

454 de Falco, B., Amato, M., Lanzotti, V., 2017a. Chia seeds products: an overview, Phytochem Rev . 455 doi: 10.1007/s11101-017-9511-7.

456 de Falco, B., Incerti, G., Bochicchio, R., Phillips, T.D., Amato, M., Lanzotti, V., 2017b. Metabolomic 457 analysis of Salvia hispanica seeds using NMR spectroscopy and multivariate data analysis, Industrial 458 Crops \& Products 99, 86-96. doi: 10.1016/j.indcrop.2017.01.019.

459 Erdemoglu, N., Kusmenoglu, S., Yenice, N., 2003. Effect of irrigation on the oil content and fatty 460 acid composition of some sunflower seeds, Chemistry of natural compounds 39, 1-4. 
461 Esteban, M.A., Villanueva, M.J., Lissarrague, J.R., 2001. Effect of irrigation on changes in the 462 anthocyanin composition of the skin of $\mathrm{cv}$ Tempranillo (Vitis vinifera $\mathrm{L}$ ) grape berries during 463 ripening, J. Sci. Food Agric. 81, 409-420.

464 Felisberto, M.H.F., Galvão, Maria Teresa Esteves Lopes, Picone, C.S.F., Cunha, R.L., Pollonio, 465 M.A.R., 2015. Effect of prebiotic ingredients on the rheological properties and microstructure of 466 reduced-sodium and low-fat meat emulsions, LWT-Food Science and Technology 60, 148-155.

467 Flagella, Z., Rotunno, T., Tarantino, E., Di Caterina, R., De Caro, A., 2002. Changes in seed yield 468 and oil fatty acid composition of high oleic sunflower (Helianthus annuus L.) hybrids in relation to 469 the sowing date and the water regime, Eur. J. Agron. 17, 221-230.

470 Gentry, H.S., Mittleman, M., McCrohan, P.R., 1990. Introduction of chia and gum tragacanth in the 471 US, , 252-256.

472 Gómez-González, S., Ruiz-Jiménez, J., Priego-Capote, F., Luque de Castro, María Dolores, 2010. 473 Qualitative and Quantitative Sugar Profiling in Olive Fruits, Leaves, and Stems by Gas 474 Chromatography- Tandem Mass Spectrometry (GC-MS/MS) after Ultrasound-Assisted Leaching, J. 475 Agric. Food Chem. 58, 12292-12299.

476 Gullberg, J., Jonsson, P., Nordström, A., Sjöström, M., Moritz, T., 2004. Design of experiments: an 477 efficient strategy to identify factors influencing extraction and derivatization of Arabidopsis thaliana 478 samples in metabolomic studies with gas chromatography/ mass spectrometry, Anal. Biochem. 331, 479 283-295. doi: 10.1016/j.ab.2004.04.037.

480 Herman, S., Marco, G., Cecilia, B., Alfonso, V., Luis, M., Cristián, V., Sebastián, P., Sebastián, A., 481 2016. Effect of water availability on growth, water use efficiency and omega 3 (ALA) content in two 482 phenotypes of chia (Salvia hispanica L.) established in the arid Mediterranean zone of Chile, Agric. 483 Water Manage. 173, 67-75.

484 Hermoso-Diaz, I., Velázquez-González, M., Lucio-Garcia, M., Gonzalez-Rodriguez, J., 2014. A 485 study of Salvia hispanica as green corrosion inhibitor for carbon steel in sulfuric acid, Chem Sci Rev 486 Lett 3, 685-697.

487 Heuer, B., Yaniv, Z., Ravina, I., 2002. Effect of late salinization of chia (Salvia hispanica), stock 488 (Matthiola tricuspidata) and evening primrose (Oenothera biennis) on their oil content and quality, 489 Industrial Crops and Products 15, 163-167.

490 Iglesias-Puig, E., Haros, M., 2013. Evaluation of performance of dough and bread incorporating chia 491 (Salvia hispanica L.), European Food Research and Technology 237, 865-874. 
IUSS, w.G., 2007. World Reference Base for Soil Resources. World Soil Resources Report 103 . Rome: Food and Agriculture Organization of the United Nations (2006), pp. 132, US\$22.00 (paperback). ISBN 92-5-10511-4, Exp. Agric. 43, 103. doi: 10.1017/S0014479706394902.

Ixtaina, V.Y., Martínez, M.L., Spotorno, V., Mateo, C.M., Maestri, D.M., Diehl, B.W., Nolasco, S.M., Tomás, M.C., 2011. Characterization of chia seed oils obtained by pressing and solvent extraction, Journal of Food Composition and Analysis 24, 166-174.

Jamboonsri, W., Phillips, T.D., Geneve, R.L., Cahill, J.P., Hildebrand, D.F., 2012. Extending the range of an ancient crop, Salvia hispanica L.-a new $\omega 3$ source, Genet. Resour. Crop Evol. 59, 171178.

Jenks, A.A., Kim, S., 2013. Medicinal plant complexes of Salvia subgenus Calosphace: an ethnobotanical study of new world sages, J. Ethnopharmacol. 146, 214-224.

Kyraleou, M., Koundouras, S., Kallithraka, S., Theodorou, N., Proxenia, N., Kotseridis, Y., 2016. Effect of irrigation regime on anthocyanin content and antioxidant activity of Vitis vinifera L. cv. Syrah grapes under semiarid conditions, J. Sci. Food Agric. 96, 988-996.

Lu, Y., Foo, L.Y., 2002. Polyphenolics of Salvia - a review, Phytochemistry 59, 117-140.

Martínez-Cruz, O., Paredes-López, O., 2014. Phytochemical profile and nutraceutical potential of chia seeds (Salvia hispanica L.) by ultra high performance liquid chromatography, Journal of Chromatography A 1346, 43-48.

Menga, V., Amato, M., Phillips, T.D., Angelino, D., Morreale, F., Fares, C., 2017. Gluten-free pasta incorporating chia (Salvia hispanica L.) as thickening agent: An approach to naturally improve the nutritional profile and the in vitro carbohydrate digestibility, Food Chem. 221, 1954-1961.

Muñoz, L.A., Cobos, A., Diaz, O., Aguilera, J.M., 2012. Chia seeds: Microstructure, mucilage extraction and hydration, J. Food Eng. 108, 216-224. doi: 10.1016/j.jfoodeng.2011.06.037.

Muñoz, L.A., Cobos, A., Diaz, O., Aguilera, J.M., 2013. Chia seed (Salvia hispanica): an ancient grain and a new functional food, Food Rev. Int. 29, 394-408.

Peiretti, P.G., Gai, F., 2009. Fatty acid and nutritive quality of chia ( Salvia hispanica L.) seeds and plant during growth, Anim. Feed Sci. Technol. 148, 267-275. doi: 10.1016/j.anifeedsci.2008.04.006. RDevelopment, C., 2012. TEAM 2009: R: A language and environment for statistical computing, Vienna, Austria.Internet: http://www.R-project.org . 
521 Re, R., Pellegrini, N., Proteggente, A., Pannala, A., Yang, M., Rice-Evans, C., 1999. Antioxidant 522 activity applying an improved ABTS radical cation decolorization assay, Free Radical Biology and 523 Medicine 26, 1231-1237. doi: 10.1016/S0891-5849(98)00315-3.

524 Reyes-Caudillo, E., Tecante, A., Valdivia-López, M.A., 2008. Dietary fibre content and antioxidant activity of phenolic compounds present in Mexican chia ( Salvia hispanica L.) seeds, Food Chem. 107, 656-663. doi: 10.1016/j.foodchem.2007.08.062.

527 Segura-Campos, M.R., Ciau-Solís, N., Rosado-Rubio, G., Chel-Guerrero, L., Betancur-Ancona, D., 2014. Chemical and functional properties of chia seed (Salvia hispanica L.) gum, International 529 journal of food science 2014.

530 Sezen, S., Yazar, A., Kapur, B., Tekin, S., 2011. Comparison of drip and sprinkler irrigation strategies 531 on sunflower seed and oil yield and quality under Mediterranean climatic conditions, Agric. Water 532 Manage. 98, 1153-1161.

533 Shareef, A., Angove, M.J., Wells, J.D., 2006. Optimization of silylation using N- methyl- N-( 534 trimethylsilyl)- trifluoroacetamide, $\mathrm{N}, \mathrm{O}-$ bis-( trimethylsilyl)- trifluoroacetamide and $\mathrm{N}-($ tert535 butyldimethylsilyl)- N-methyltrifluoroacetamide for the determination of the estrogens estrone and $53617 \alpha$ - ethinylestradiol by gas chromatography- mass spectrometry, Journal of Chromatography A 537 1108, 121-128. doi: 10.1016/j.chroma.2005.12.098.

538 Sheisa Cyléia Sargi, Beatriz, C.S., Hevelyse Munise, C.S., Paula, F.M., Joana, S.B., Oscar Oliveira, 539 S.J., Nilson Evelázio Souza, Jesuí Vergílio Visentainer, 2013. Antioxidant capacity and chemical 540 composition in seeds rich in omega- 3: chia, flax, and perilla, Food Science and Technology 33, 541541 548. doi: 10.1590/S0101-20612013005000057.

542 Silva, H., Garrido, M., Baginsky, C., Valenzuela, A., Morales, L., Valenzuela, C., Pavez, S., Alister, 543 S., 2016. Effect of water availability on growth, water use efficiency and omega 3 (ALA) content in 544 two phenotypes of chia (Salvia hispanica L.) established in the arid Mediterranean zone of Chile, 545 Agric. Water Manage. 173, 67-75.

546 Singleton, V., Rossi, J.A., 1965. Colorimetry of total phenolics with phosphomolybdic547 phosphotungstic acid reagents, Am. J. Enol. Vitic. 16, 144-158.

548 Švec, I., Hrušková, M., Jurinová, I., 2016. Pasting characteristics of wheat-chia blends, J. Food Eng. $549 \quad 172,25-30$.

550 Vázquez-Ovando, A., Rosado-Rubio, G., Chel-Guerrero, L., Betancur-Ancona, D., 2009. 551 Physicochemical properties of a fibrous fraction from chia ( Salvia hispanica L.), Food science and 
technology; Physicochemical properties of a fibrous fraction from chia (Salvia hispanica L.) 42, 168-

553173.

554 Vuksan, V., Jenkins, A., Dias, A., Lee, A., Jovanovski, E., Rogovik, A., Hanna, A., 2010. Reduction 555 in postprandial glucose excursion and prolongation of satiety: possible explanation of the long-term 556 effects of whole grain Salba (Salvia hispanica L.), Eur. J. Clin. Nutr. 64, 436.

557 Wu, G., Johnson, S.K., Bornman, J.F., Bennett, S.J., Fang, Z., 2017. Changes in whole grain 558 polyphenols and antioxidant activity of six sorghum genotypes under different irrigation treatments, 559 Food Chem. 214, 199-207.

560 Zhang, J., Kirkham, M., 1996. Antioxidant responses to drought in sunflower and sorghum seedlings, 561 New Phytol. 132, 361-373.

\section{TABLES}

567 Table 1 Polar and non-polar metabolites assigned in Chia seeds by GC-MS

\begin{tabular}{|c|c|c|c|c|c|}
\hline Peak & Detected metabolite & Abbreviation & $\mathrm{RT}$ (min) & $\begin{array}{l}\text { Molecular } \\
\text { formula }\end{array}$ & $m / z$ \\
\hline \multicolumn{6}{|l|}{ Polar } \\
\hline 1 & Lactic Acid & LA & 7.25 & $\mathrm{C}_{9} \mathrm{H}_{22} \mathrm{O}_{3} \mathrm{Si}_{2}$ & $219,191,147,133,117,73,45$ \\
\hline 2 & $\begin{array}{l}\text { Methyl 2-ethyl } \\
\text { malonate }\end{array}$ & Me-MA & 7.32 & $\mathrm{C}_{9} \mathrm{H}_{18} \mathrm{O}_{4} \mathrm{Si}$ & $175,89,73$ \\
\hline 3 & $\begin{array}{l}\text { L-Alanine, N-methyl-N- } \\
\text { (trifluoroacetyl)-, butyl } \\
\text { ester }\end{array}$ & Ala, Nm-Tfa-Obu & 9.99 & $\mathrm{C}_{10} \mathrm{H}_{16} \mathrm{~F}_{3} \mathrm{NO}_{3}$ & 154,110 \\
\hline 4 & Benzoic Acid & $\mathrm{BE}$ & 10.03 & $\mathrm{C}_{10} \mathrm{H}_{14} \mathrm{O}_{2} \mathrm{Si}$ & $194,179,135,105,77$ \\
\hline 5 & Glycerol & GLY & 10.46 & $\mathrm{C}_{12} \mathrm{H}_{32} \mathrm{O}_{3} \mathrm{Si}_{3}$ & $218,205,147,117,89,73,45$ \\
\hline 6 & L-serine & Ser & 11.74 & $\mathrm{C}_{12} \mathrm{H}_{31} \mathrm{NO}_{3} \mathrm{Si}_{3}$ & $218,204,147,100,73$ \\
\hline 7 & L-Threonine & Thr & 12.14 & $\mathrm{C}_{13} \mathrm{H}_{33} \mathrm{NO}_{3} \mathrm{Si}_{3}$ & $291,218,147,117,73$ \\
\hline 8 & $\mathrm{~N}-\alpha$-Acetyl-L-Lysine & AcLys & 13.04 & $\mathrm{C}_{17} \mathrm{H}_{40} \mathrm{~N}_{2} \mathrm{O}_{3} \mathrm{Si}_{3}$ & $404,287,73$ \\
\hline 9 & Malic acid & MA & 13.52 & $\mathrm{C}_{13} \mathrm{H}_{30} \mathrm{O}_{5} \mathrm{Si}_{3}$ & $245,233,147,133,73$ \\
\hline 10 & L-Aspartic acid & Asp & 13.97 & $\mathrm{C}_{13} \mathrm{H}_{31} \mathrm{NO}_{4} \mathrm{Si}_{3}$ & $232,218,147,100,73$ \\
\hline 11 & L-5-Oxoproline & PCA & 14.00 & $\mathrm{C}_{11} \mathrm{H}_{23} \mathrm{NO}_{3} \mathrm{Si}_{2}$ & $258,230,156,133,73,45$ \\
\hline 12 & L-Glutamic acid & Glu & 15.21 & $\mathrm{C}_{14} \mathrm{H}_{33} \mathrm{NO}_{4} \mathrm{Si}_{3}$ & $246,147,128,73$ \\
\hline 13 & Phenylalanine & Phe & 15.35 & $\mathrm{C}_{15} \mathrm{H}_{27} \mathrm{NO}_{2} \mathrm{Si}_{2}$ & $218,192,147,100,73$ \\
\hline 14 & Tartaric acid & TA & 15.54 & $\mathrm{C}_{28} \mathrm{H}_{62} \mathrm{O}_{6} \mathrm{Si}_{4}$ & $549,417,389,147,73$ \\
\hline 15 & Citric acid & $\mathrm{Cl}$ & 17.69 & $\mathrm{C}_{18} \mathrm{H}_{40} \mathrm{O}_{7} \mathrm{Si}_{4}$ & $273,147,73,45$ \\
\hline 16 & Methyl galactoside & mGal & 17.77 & $\mathrm{C}_{19} \mathrm{H}_{46} \mathrm{O}_{6} \mathrm{Si}_{4}$ & $243,217,204,133,73$ \\
\hline 17 & Quininic acid & QUI & 18.24 & $\mathrm{C}_{22} \mathrm{H}_{52} \mathrm{O}_{6} \mathrm{Si}_{5}$ & $345,255,191,147,73$ \\
\hline 18 & D-Fructose MEOX & FRU & 18.37 & $\mathrm{C}_{22} \mathrm{H}_{55} \mathrm{NO}_{6} \mathrm{Si}_{5}$ & 217,307 \\
\hline 19 & Arabitol & Ara & 18.48 & $\mathrm{C}_{20} \mathrm{H}_{52} \mathrm{O}_{5} \mathrm{Si}_{5}$ & $307,277,217,189,147,103,73$ \\
\hline
\end{tabular}




\begin{tabular}{|c|c|c|c|c|c|}
\hline 20 & D-Galactose MEOX & Gal & 18.61 & $\mathrm{C}_{22} \mathrm{H}_{55} \mathrm{NO}_{6} \mathrm{Si}_{5}$ & $319,205,147,103,73$ \\
\hline 21 & D-Glucose MEOX & Glc & $18.67 ; 18.86$ & $\mathrm{C}_{22} \mathrm{H}_{55} \mathrm{NO}_{6} \mathrm{Si}_{5}$ & $364,319,205,147,73$ \\
\hline 22 & D-Mannitol & MAN & 19.04 & $\mathrm{C}_{24} \mathrm{H}_{62} \mathrm{O}_{6} \mathrm{Si}_{6}$ & $421,345,319,205,147,103,73$ \\
\hline 23 & D-Gluconic acid & GLUC & 19.77 & $\mathrm{C}_{24} \mathrm{H}_{60} \mathrm{O}_{7} \mathrm{Si}_{6}$ & $333,292,205,147,103,73$ \\
\hline 24 & $\begin{array}{l}\text { Trimethylsilyl } \\
\text { catechollactate } \\
\text { tris(trimethylsilyl) ether }\end{array}$ & Cat & 20.30 & $\mathrm{C}_{21} \mathrm{H}_{42} \mathrm{O}_{5} \mathrm{Si}_{4}$ & $396,267,179,147,73$ \\
\hline 25 & Myo-Inositol & Myo & 20.69 & $\mathrm{C}_{24} \mathrm{H}_{60} \mathrm{O}_{6} \mathrm{Si}_{6}$ & $305,217,147,129,73$ \\
\hline 26 & Caffeic acid & $\mathrm{CA}$ & 20.91 & $\mathrm{C}_{18} \mathrm{H}_{32} \mathrm{O}_{4} \mathrm{Si}_{3}$ & $396,381,219,191,73$ \\
\hline 27 & Sucrose & Sucr & 25.66 & $\mathrm{C}_{36} \mathrm{H}_{86} \mathrm{O}_{11} \mathrm{Si}_{8}$ & $\begin{array}{l}437,361,319,271,217,147 \\
103,73\end{array}$ \\
\hline \multicolumn{6}{|c|}{ Apolar } \\
\hline 28 & Palmitic Acid & C16:0 & 17.88 & $\mathrm{C}_{19} \mathrm{H}_{40} \mathrm{O}_{2} \mathrm{Si}$ & $328,313,145,117,73$ \\
\hline 29 & Linoleic acid & C18:2 & 19.54 & $\mathrm{C}_{21} \mathrm{H}_{40} \mathrm{O}_{2} \mathrm{Si}$ & $337,129,95,75,73$ \\
\hline 30 & $\alpha$-Linolenic acid & C18:3 & 19.61 & $\mathrm{C}_{21} \mathrm{H}_{38} \mathrm{O}_{2} \mathrm{Si}$ & $335,129,95,75,73$ \\
\hline 31 & Stearic acid & C18:0 & 19.80 & $\mathrm{C}_{21} \mathrm{H}_{44} \mathrm{O}_{2} \mathrm{Si}$ & $356,341,132,117,73$ \\
\hline 32 & Oleic acid & C18:1 & 22.07 & $\mathrm{C}_{21} \mathrm{H}_{42} \mathrm{O}_{2} \mathrm{Si}$ & $354,339,129,117,73$ \\
\hline 33 & 10-Heptadecenoic acid & C17:1 & 24.05 & $\mathrm{C}_{20} \mathrm{H}_{40} \mathrm{O}_{2} \mathrm{Si}$ & $340,325,145,129,117,73$ \\
\hline 34 & Glycerol monostearate & GMS & 24.34 & $\mathrm{C}_{27} \mathrm{H}_{58} \mathrm{O}_{4} \mathrm{Si}_{2}$ & $487,399,147,73$ \\
\hline
\end{tabular}

568 
570 Table 2 Analysis of variance on polar and non-polar fraction to evaluate the effect of genotype and $571 \quad$ irrigation on Chia seeds

\begin{tabular}{|c|c|c|c|}
\hline Compounds & Genotype & Irrigation & $\begin{array}{c}\text { Genotype } \mathrm{x} \\
\text { Irrigation }\end{array}$ \\
\hline \multicolumn{4}{|l|}{ Polar } \\
\hline LA & $\mathrm{p}<0.05$ & n.s. & $\mathrm{p}<0.05$ \\
\hline Me-MA & n.s. & n.s. & n.s. \\
\hline Ala-Obu & n.s. & n.s. & n.s. \\
\hline $\mathrm{BE}$ & $\mathrm{p}<0.05$ & n.s. & n.s. \\
\hline GLY & n.s. & n.s. & $\mathrm{p}<0.05$ \\
\hline Ser & $\mathrm{p}<0.05$ & n.s. & n.s. \\
\hline Thr & n.s. & n.s. & n.s. \\
\hline AcLys & n.s. & n.s. & n.s. \\
\hline MA & n.s. & n.s. & n.s. \\
\hline Asp & $\mathrm{p}<0.01$ & n.s. & $\mathrm{p}<0.05$ \\
\hline PCA & n.s. & n.s. & n.s. \\
\hline Glu & n.s. & n.s. & n.s. \\
\hline Phe & n.s. & n.s. & $\mathrm{p}<0.05$ \\
\hline TA & n.s. & n.s. & n.s. \\
\hline CI & n.s. & n.s. & n.s. \\
\hline $\mathrm{mGal}$ & n.s. & n.s. & n.s. \\
\hline QUI & n.s. & n.s. & n.s. \\
\hline FRU & n.s. & n.s. & n.s. \\
\hline Ara & $\mathrm{p}<0.05$ & n.s. & n.s. \\
\hline Gal & n.s. & n.s. & n.s. \\
\hline Glc & n.s. & n.s. & n.s. \\
\hline MAN & $\mathrm{p}<0.01$ & n.s. & n.s. \\
\hline GLUC & $\mathrm{p}<0.01$ & n.s. & n.s. \\
\hline Cat & n.s. & n.s. & n.s. \\
\hline Мyо & n.s. & n.s. & n.s. \\
\hline $\mathrm{CA}$ & n.s. & n.s. & n.s. \\
\hline Sucr & n.s. & n.s. & n.s. \\
\hline GABA & n.s. & n.s. & n.s. \\
\hline \multicolumn{4}{|l|}{ Non-polar } \\
\hline C16:0 & $\mathrm{P}<0.05$ & $\mathrm{P}<0.001$ & n.s. \\
\hline C18:2 & $\mathrm{P}<0.01$ & $\mathrm{P}<0.0001$ & n.s. \\
\hline C18:3 & $\mathrm{P}<0.01$ & $\mathrm{P}<0.0001$ & n.s. \\
\hline C18:0 & $\mathrm{P}<0.01$ & $\mathrm{P}<0.0001$ & n.s. \\
\hline C18:1 & n.s. & $\mathrm{P}<0.0001$ & $\mathrm{P}<0.01$ \\
\hline C17:1 & $\mathrm{P}<0.01$ & $\mathrm{P}<0.0001$ & n.s. \\
\hline GMS & n.s. & n.s. & $\mathrm{P}<0.01$ \\
\hline
\end{tabular}


576 Figure 1. Growth environment data and interaction of genotype $\mathrm{x}$ irrigation for yield and chemical properties of Chia seeds (Salvia hispanica L.). Left: temperature, precipitation and irrigation amounts during crop growth (top); seed yield and oil content (bottom). Different lower case letters indicate significant differences $(\mathrm{p}<0.05)$ at the post-hoc Tukey's test. Right: Total polyphenol content (top) and Antioxidant activity (bottom) of defatted Chia seeds. Within each time different upper case letters 581 indicate highly significant differences $(\mathrm{p}<0.01)$ at the post-hoc Tukey's test.

583 Figure 2. Representative TIC of the polar (A) and non-polar (B) fractions of Chia seeds extracts. 584 Peaks correspond to numbering of compounds in Table 1

Figure 3. Metabolites belonging to different classes of compounds of non-polar extract of Chia seeds detected by GC/MS analysis. The Y-axis indicates the relative quantification obtained by integrating the peak areas of the chromatographic profiles for each compound and normalizing the data to the internal standards. Top left: main effects of genotype; top right: main effect of irrigation; bottom left: interaction of genotype $\mathrm{x}$ irrigation. Within each compound different upper case letters indicate highly significant differences $(\mathrm{p}<0.01)$ and different lower case letters indicate significant differences $(p<0.05)$ at the analysis of variance for main effects and at the post-hoc Tukey's test for the interaction.

Figure 4. Metabolites belonging to different classes of compounds of non-polar extract of Chia seeds detected by GC/MS analysis. The Y-axis indicates the relative quantification obtained by integrating the peak areas of the chromatographic profiles for each compound and normalizing the data to the internal standards. Top left: overall average for compounds not significantly different between treatments; top right: main effect of genotype for compounds significantly different between G8 and B; bottom left: interaction of genotype $\mathrm{x}$ irrigation; within each compound different lower case letters indicate significant differences $(\mathrm{p}<0.05)$ at the post-hoc Tukey's test for the interaction. 

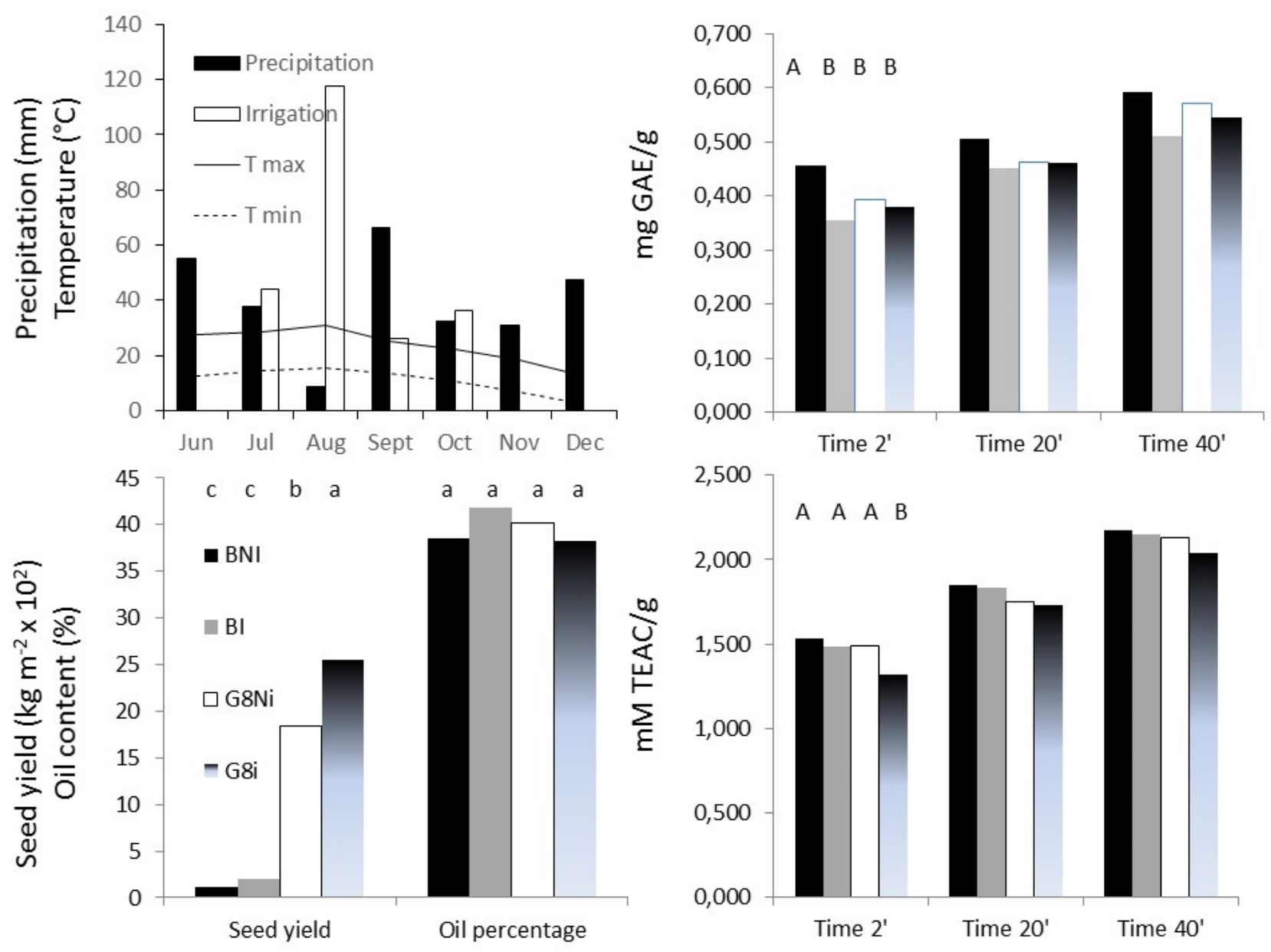

Figure 1 

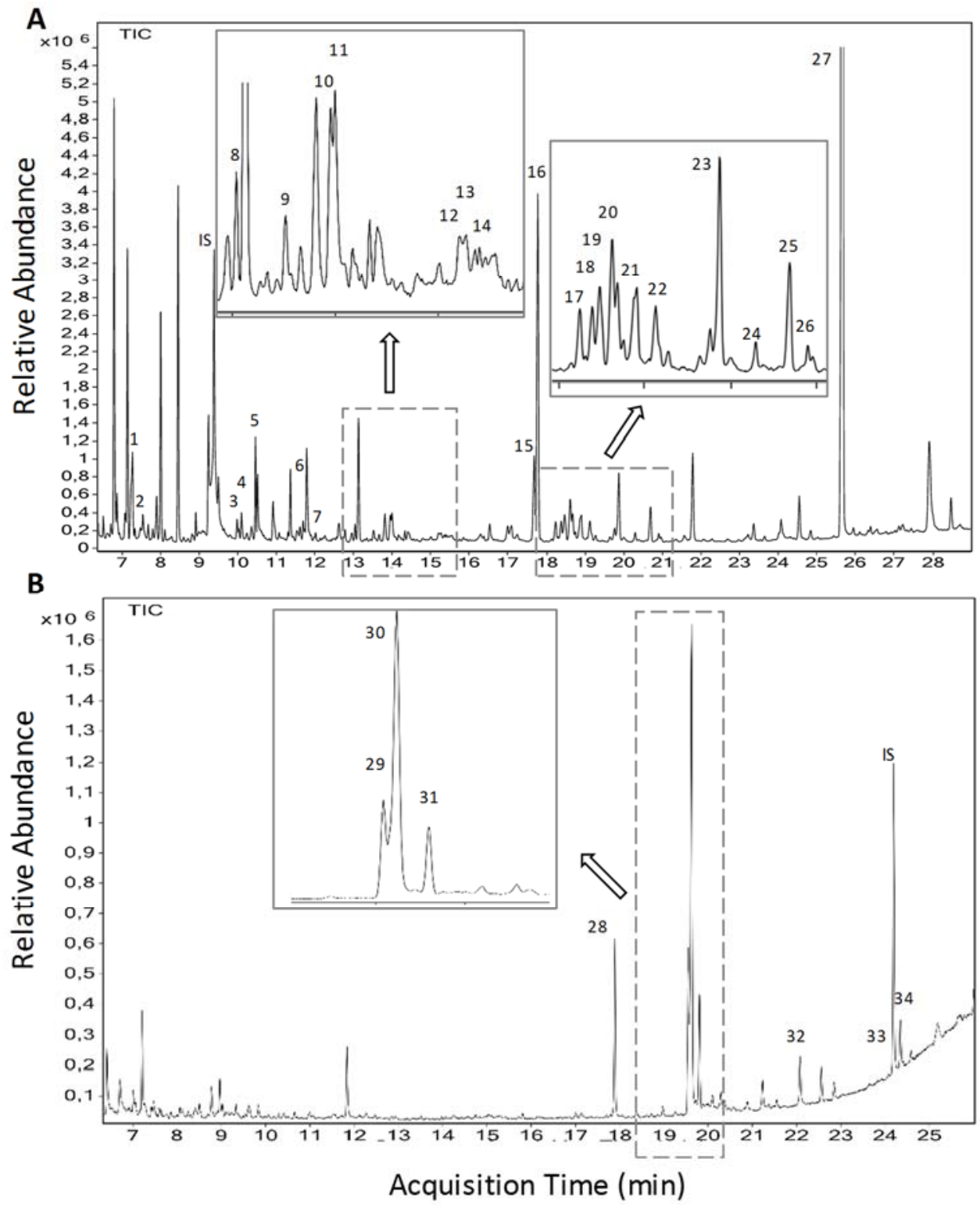

Figure 2. 

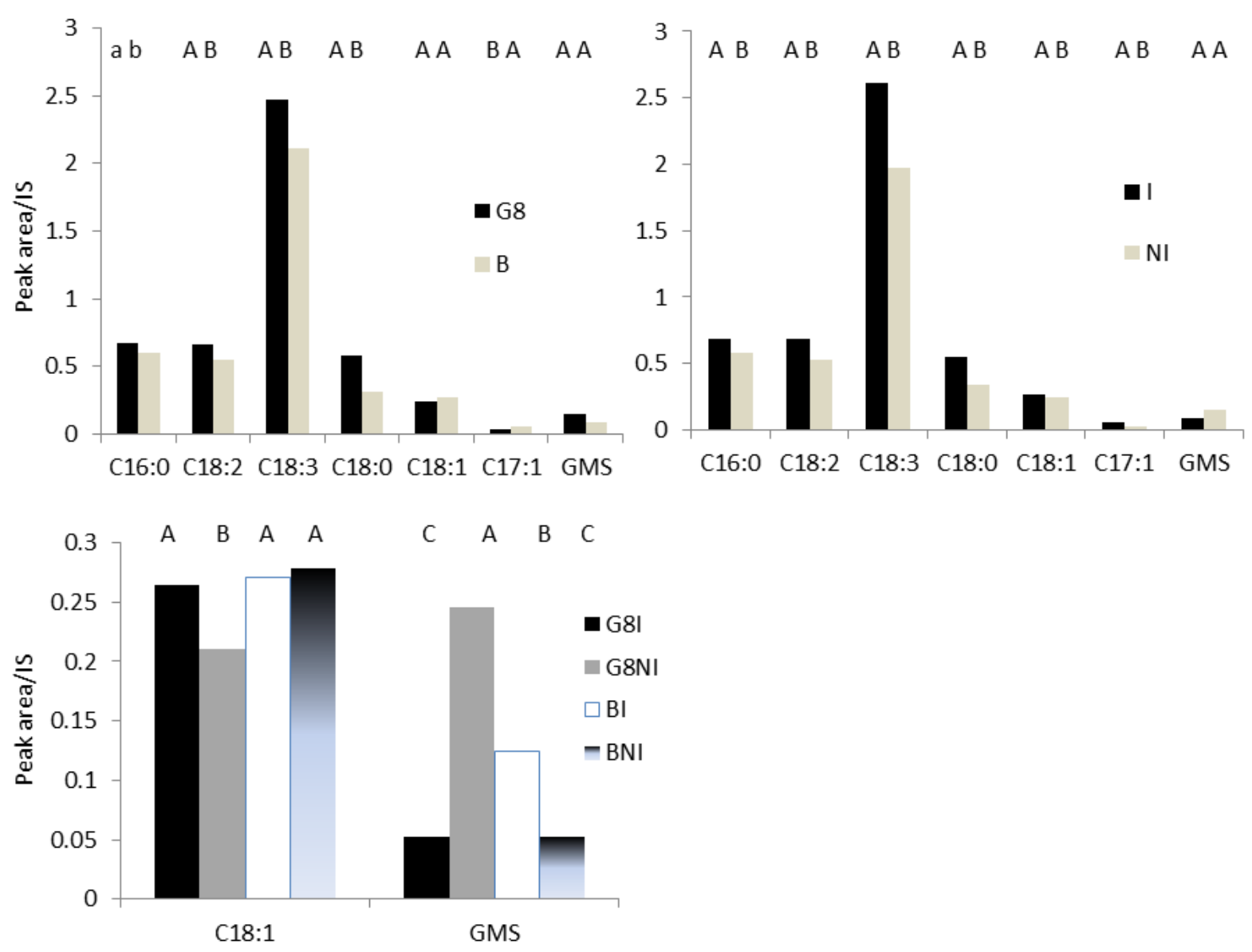

Figure 3 

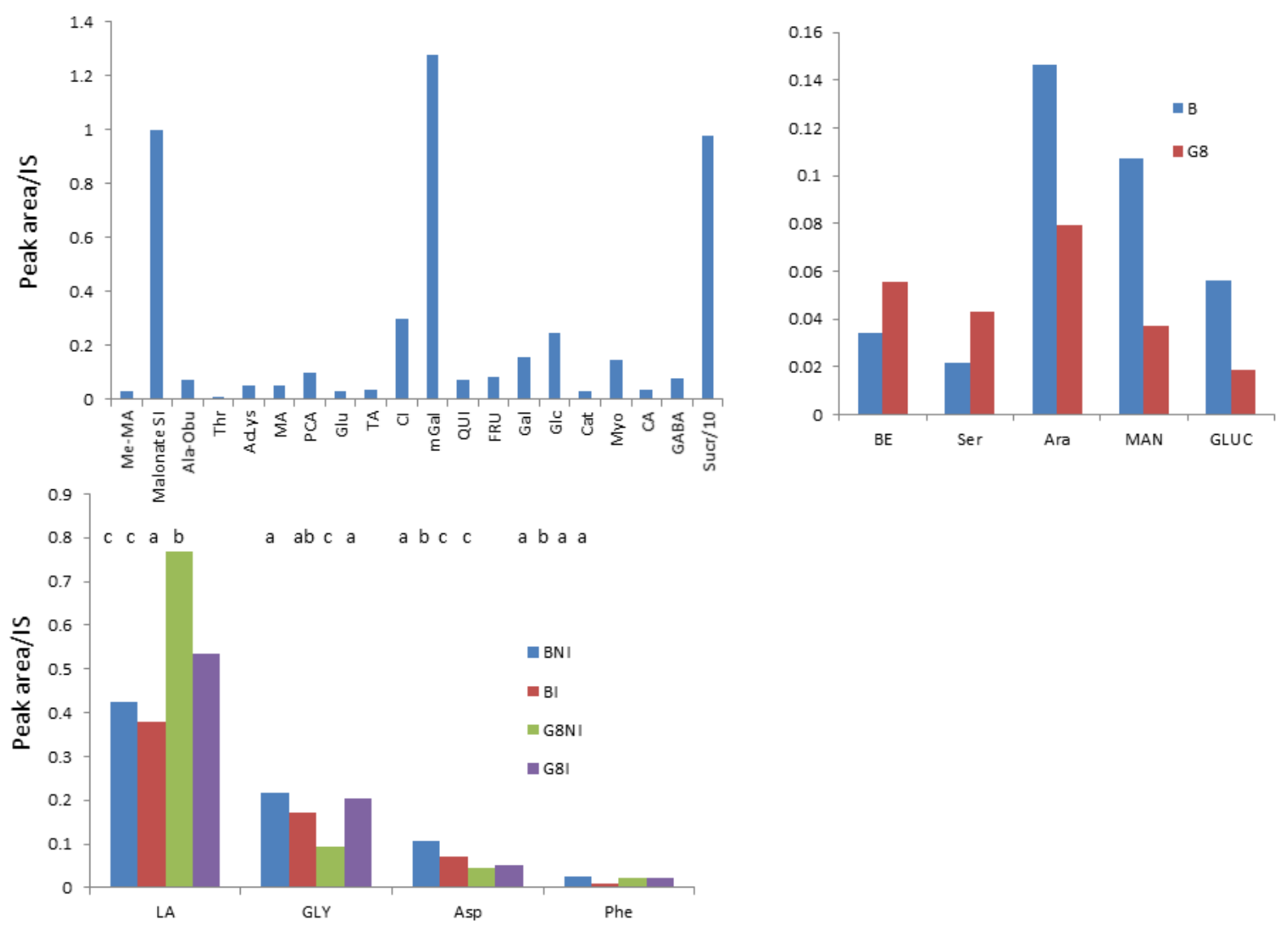

Figure 4 